\title{
The role of cardiac CT during the COVID-19 pandemic
}

\section{(D) Mladen Jukić*}

Special Hospital AGRAM, Zagreb, Croatia
RECEIVED:

December 14, 2020

ACCEPTED:

December 18, 2020

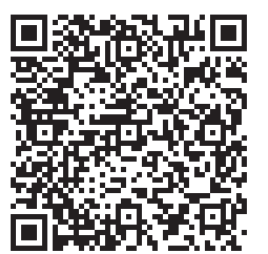

KEYWORDS: coronary computed tomography angiography, COVID-19, invasive cardiology. CITATION: Cardiol Croat. 2021;16(1-2):53. | https://doi.org/10.15836/ccar2021.53

*ADDRESS FOR CORRESPONDENCE: Mladen Jukić, Specijalna bolnica Agram, Trnjanska cesta 108, HR-10000 Zagreb, Croatia. / Phone: +385-99-2178323 / E-mail: mladen.jukic@agram-bolnica.hr

ORCID: Mladen Jukić, https://orcid.org/0000-0002-3927-3888

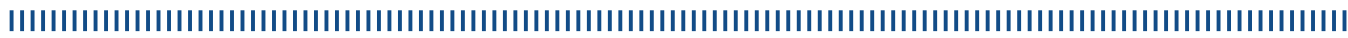

Main role of coronary computed tomography angiography (CCTA) is to rule out obstruction in patients with suspected coronary artery disease (but no ST-elevation myocardial infarction), and to alleviate invasive cardiology of unnecessary diagnostic procedures. This is especially useful in situation of COVID-19 pandemic, since CCTA can be performed in outpatient setting, with very short times of personnel to patient exposure. ${ }^{1}$ In 2020 we had 1393 patients on CCTA (a 30\% increase from 2019), and in $69 \%$ we excluded obstructive coronary artery disease. We believe this shows that CCTA as first line strategy can, when appropriate, relieve invasive cardiology, and comparatively reduce COVID-19 transmission channels 